\title{
Hearing and stomatognathic system: Searching for a link
}

\section{Stan układu stomatognatycznego a proces słyszenia}

\author{
Sławomir Baliński, ${ }^{1, A-D, F}$, Monika Morawska-Kochmann ${ }^{2, A, C E}$, Marek Bochnia ${ }^{3, A, C-F}$ \\ 1Private Dental Practice, Świdnica, Poland \\ 2 Department and Clinic of Otolaryngology Head and Neck Surgery, Wroclaw Medical University, Wrocław, Poland \\ ${ }^{3}$ Department of Otolaryngology, Faculty of Dentistry, Wroclaw Medical University, Wrocław, Poland \\ A - research concept and design; $\mathrm{B}$ - collection and/or assembly of data; $\mathrm{C}$ - data analysis and interpretation; \\ $D$ - writing the article; $E$ - critical revision of the article; $F$ - final approval of the article
}

Address for correspondence

Monika Morawska-Kochman

E-mail:mkochman@mp.pl

\section{Funding sources}

None declared

Conflict of interest

None declared

Received on June 6, 2017

Reviewed on July 28, 2017

Accepted on October 18, 2017

\begin{abstract}
Acoustic vibrations reach the inner ear fluids in 3 integral ways: through the air, bone, and soft tissue. The final stimulation of the hearing receptor is recognized as the result of various interactions appearing between them. Air conduction is best described as the most efficient mode of auditory stimulation. Soft tissue and bone conduction (including dentaural hearing), being frequently underestimated in the complicated process of hearing, are still less examined. Clinical observations prove that dental health may have a direct influence on hearing. Additionally, hearing improvement after dental treatment is of a permanent nature.

This review presents a hypothesis and supporting literature review that dental disorders may contribute to disturbances in the excitation and/or the transmission of vibrations through the bone to the hearing receptor. Dissociation in the relationship between stimuli reaching the cochlea simultaneously in 3 modes may have a negative impact on hearing acuity.
\end{abstract}

Key words: bone conduction, acoustic stimulation, dentition

Słowa kluczowe: przewodnictwo kostne, stymulacja akustyczna, uzębienie

D0I

$10.17219 / \mathrm{dmp} / 78718$

Copyright

(-) 2017 by Wroclaw Medical University

and Polish Dental Society

This is an article distributed under the terms of the

Creative Commons Attribution Non-Commercial License

(http://creativecommons.org/licenses/by-nc-nd/4.0/) 


\section{Introduction}

The entire human body is continuously affected by the sound fields. In the process of hearing, acoustic energy reaches the inner ear fluids in 3 integral ways: through the air, bone, and soft tissue. In spite of a few dissimilarities reported, the stimulation of hearing receptors (HR) does not depend onthe route through which the impulses reach the cochlea. ${ }^{1-3}$

\section{Modes, pathways, and mechanisms of sound energy transmission}

\section{Air conduction (AC)}

The conductive apparatus transmits sound through 2 pathways. The main one (ossicular) leads through the auricle, external auditory meatus (EAM), tympanic membrane (TM), ossicular chain, and the oval window to the fluids and other structures of the inner ear (IE). In the second, less effective pathway (acoustic), TM vibrations are transmitted to the surrounding air in the tympanic cavity, to membranes in cochlear windows, and further to the IE fluids. Differences in acoustic impedance between the air and IE fluids would cause only $0.1 \%$ of the initial acoustic energy to reach the HR. Elements of the outer and middle ear can, however, compensate for half of the acoustic energy loss. The large pinna of some animals is able to move in a desired direction, which can significantly increase hearing acuity. In the human EAM, the transmitted waves are amplified up to $20 \mathrm{~dB}$ at frequencies between $1-2.5 \mathrm{kHz}$. The TM and the ossicles act as a very efficient mechanical energy transformer. The sum of all their compensatory mechanisms result in an almost 44-fold amplification of acoustic energy. ${ }^{4-6}$

\section{Bone conduction (BC)}

In physiological conditions, the bone-hearing component is yet not considered to be significant. It is the result of large differences in acoustic impedance between the air and the solid structures of the skull. Additionally, the sound dampening properties of the soft tissues of the head cannot be ignored.7,8 These limitations do not apply during fetal life, when a fetus is only able to register through $\mathrm{BC}$ sounds which reach amniotic fluids. ${ }^{9}$ In indirect $\mathrm{BC}$, acoustic waves in the surrounding air cause vibrations of the skull bone (SB) that are transmitted to the IE structures. The efficiency of HR stimulation depends on the energy of the acoustic wave and on the area of the skull that it reaches. ${ }^{10}$ The acoustic stimulus is weakened here by about $50 \mathrm{~dB}$. In direct $\mathrm{BC}$, a tuning fork or vibrator directly contacts the head of the subject. The efficacy of stimulation depends on the place of the application and on the area of the transducer and applied static pressure. ${ }^{11,12}$ The acoustic waves are weakened in this mechanism by about 30-40 dB. Each time, the vibrations may simultaneously go directly to both the bony labyrinth (cochlear pathway) and to the walls of the EAM, deforming them and producing sound in the ear canal and beyond as in the AC pathway (tympanic pathway). Tonndorf, in experiments on cats, described seven simultaneous mechanisms of $\mathrm{BC}$ stimulation of the HR. ${ }^{13}$ Presently, 4 mechanisms of vibration transmission to the fluids of the IE are generally accepted and 1 still persists as disputable.

\section{Compression of the cochlea}

Skull vibrations alternately compress and decompress the bony labyrinth. ${ }^{14}$ This mechanism relates especially to vibrations of high frequencies and is recognized as the most important contributor to HR stimulation above $4 \mathrm{kHz} .{ }^{15,16}$

\section{Inertia of the cochlear fluids}

In the vibrating cochlea, the fluid is also under the influence of inertial forces. ${ }^{16}$ Fluid inertia is recognized as the second most valid mechanism in $\mathrm{BC}$ hearing. In a normal ear, it most convincingly explains the perception of sound from low frequencies to about $4 \mathrm{kHz} .^{17,18}$

\section{Inertia of the ossicles}

The accepted basis of this mechanism resembles the activity of a mechanical spring when compared to the activity of the TM and the annular ligament with the attached ossicles. ${ }^{16}$ It has been indicated that the inertia of the ossicles can have an important influence on $\mathrm{BC}$ perception from approximately $1.5 \mathrm{kHz}$ to $3 \mathrm{kHz} .{ }^{19}$

\section{Occlusion}

During occlusion, the sound energy emitted by the motion of parts of the EAM is trapped and transmitted to the TM. ${ }^{15}$ Sound pressure in the EAM generally increases from low frequencies to no more than $2 \mathrm{kHz} .{ }^{20}$ When the EAM is opened, occlusion is acknowledged to be of limited importance in the complex process of hearing. ${ }^{21}$

\section{Cerebrospinal fluid (CSF) pathway}

SB vibrations induce vibrations in the underlying structures of the brain. Extensive studies have confirmed the transmission of sound pressures into the contents of the skull and directly through the fluid connections between CSF and the perilymph, from low frequencies up to about $3 \mathrm{kHz}$ (Fig. 1). ${ }^{11,22-24}$

\section{Soft tissue conduction (STC)}

STC has seldom been examined and applied. One exception is the Lewis-Federici test, which depends primarily on comparing the duration of BC and "bone-cartilage conduction" (fork applied to the tragus). In normal hearing and 


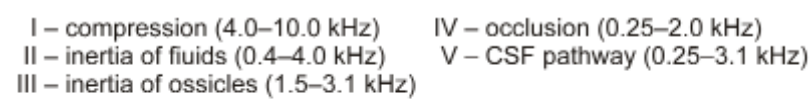
III - inertia of ossicles $(1.5-3.1 \mathrm{kHz}$

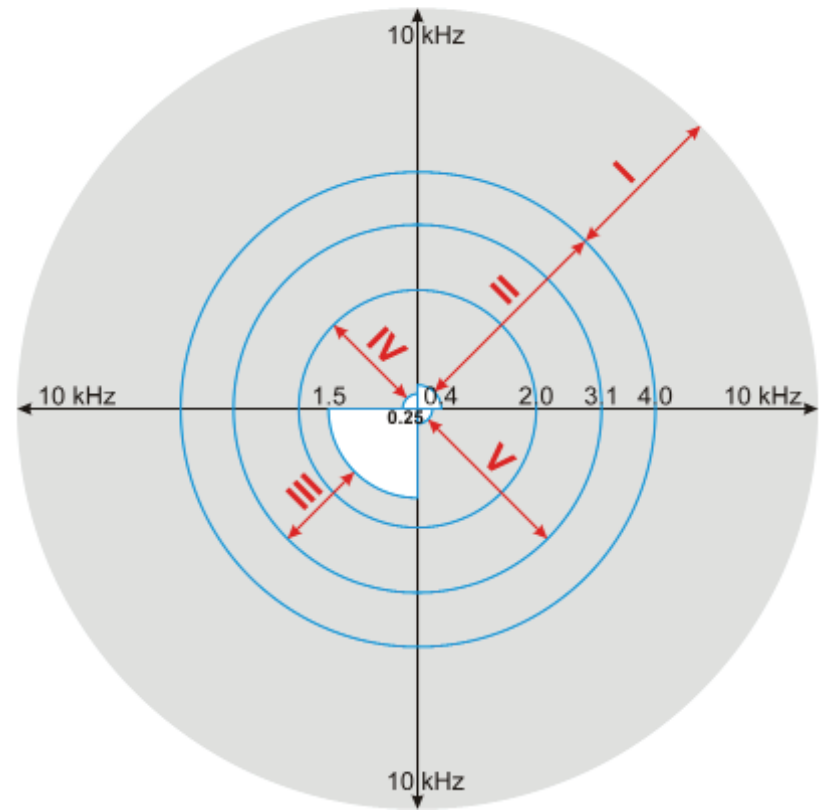

Fig. 1. Frequency ranges of hearing in the five mechanisms of transmission of skull vibrations

in sensorineural hearing loss (SNHL) - as opposed to CHL (conductive hearing loss) - the duration of the fork vibration is longer. In STC, the tuning fork may be applied to several sites, not only on the head but also on the neck and thorax of the subject. ${ }^{3,25}$ Most likely, stimulation at such a distance from the SB and the vestibule cannot be effected by BC. Part of the vibrational energy induced in the soft tissue is also reflected in the boundary with bone. ${ }^{11}$ Transmission of soft tissue vibration to the perilymph should follow along and from one to the other environment of similar acoustic impedance.
Ito et al. assessed thresholds in the frequency range of $0.25-4 \mathrm{kHz}$ in response to stimulation at different sites on the human head. ${ }^{26}$ An accelerometer measuring SB vibrations was attached to the teeth. BC thresholds measured with stimulation at the eye and forehead were higher, although strengths in acceleration at frequencies $2-4 \mathrm{kHz}$ were equal to or larger than those with stimulation at the mastoid and temporal region. The authors concluded that there are different mechanisms of HR stimulation through vibrations of soft tissue and SB. Earlier, STC was also called non-osseous $\mathrm{BC}$ and frequently not separated from BC. ${ }^{15,26}$ STC involves yet another singular mechanism and pathway, and may be recognized as entirely different from $\mathrm{AC}$ and $\mathrm{BC}$ modes of auditory stimulation.

The final complex stimulation of HR results from the total amount of energy as well as from the phases of vibratory forces. Because they reach the perilymph simultaneously, an interaction takes place between them. These vibrations can be amplified, suppressed, or even cancelled before the contribution of hearing cells. ${ }^{3,24,27,28}$ Obrębowski even put forward the radical opinion that, under physiological circumstances, BC sounds are unwanted and, if at all possible, damped. ${ }^{29}$ However, Beethoven is an example of making use of the "unappreciated" BC. This unusual musician, who was gradually losing his hearing, composed music while holding a bony stick in his teeth and resting it on his piano. The vibrations from the instrument, transmitted through the stick, could reach his IE. This was probably the first application of the variety of BC "dentaural hearing" (DH). We hope that a review of the modes, pathways, and mechanisms present in the complex process of hearing ought to simplify the detection of a possible connection between hearing acuity and dental condition (Fig. 2).

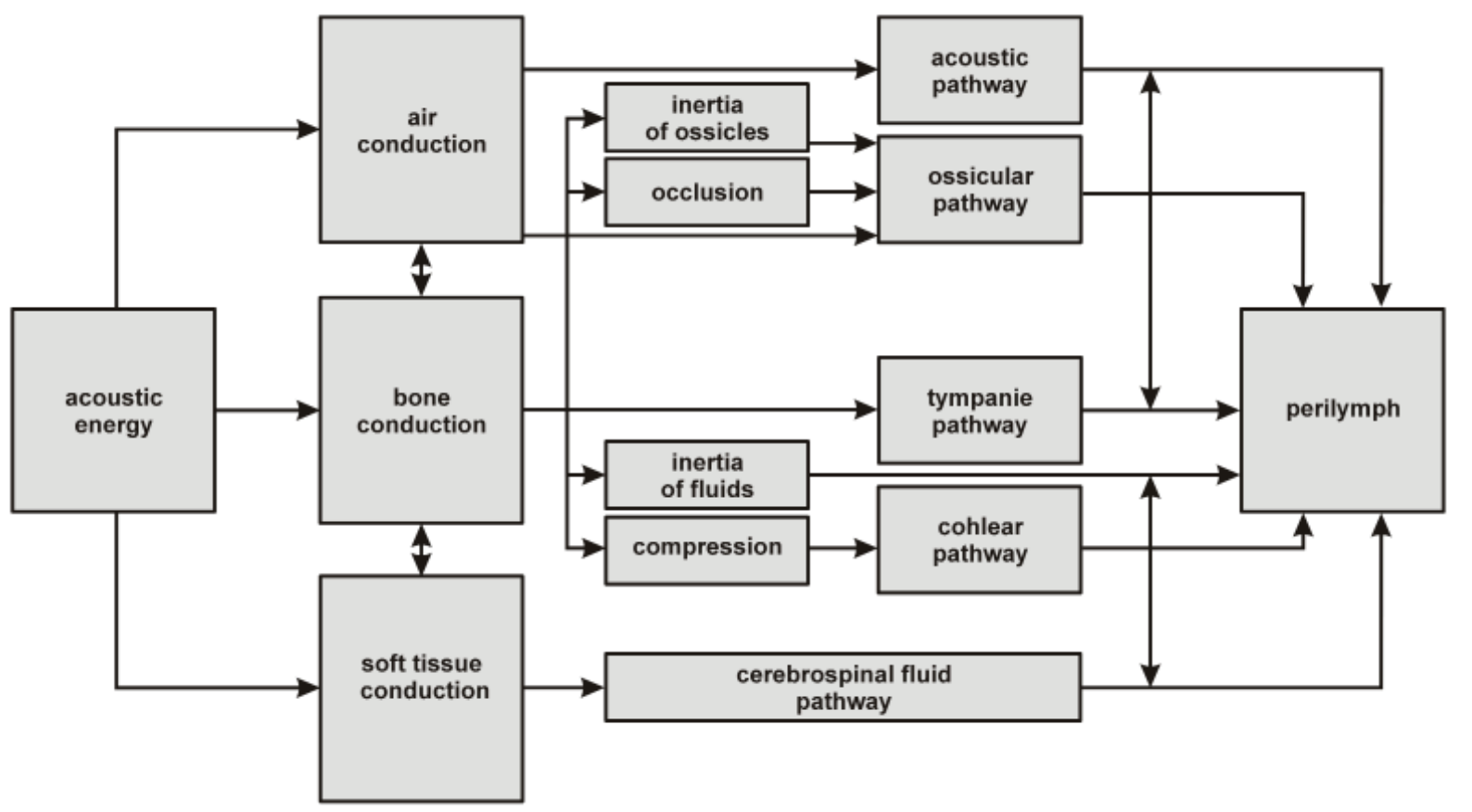

Fig. 2. Pathways and mechanisms of the hearing receptor stimulation through air, bone, and soft tissue (mutual relationships) 


\section{Mechanical properties of the skull}

The uniqueness of each skull's vibrational characteristics is probably due to various geometrical variations and differences in the mechanical properties of 3-layered SB. ${ }^{30,31}$

However, some regularity can be observed here. Bekesy was of the opinion that - at low frequencies - the skull behaves like a rigid body, i.e. below $0.8 \mathrm{kHz}$ it vibrates entirely. ${ }^{32}$ At higher frequencies, some deformities might occur which result from the division of the skull into separate oscillating parts. ${ }^{32}$ According to Huizing, the whole head, not only the skull itself, is assumed to be a system of separately vibrating segments with their mutual couplings. ${ }^{17,33}$ On this point, Semczuk noted that not only the entire maxilla, but even its set of teeth, can constitute one of the oscillating elements. ${ }^{34}$

Presently, using the results of direct $\mathrm{BC}$ examination, it has been shown that, at frequencies ranging up to $10 \mathrm{kHz}$, a few types of skull vibration appear. At the lowest frequencies, e.g. below $0.3-0.4 \mathrm{kHz}$, the skull truly moves as whole and behaves like a rigid body. ${ }^{8,16}$ At a frequency of about $1 \mathrm{kHz}$, the first global resonance appears. ${ }^{35}$ From $0.3-0.4 \mathrm{kHz}$ to $1 \mathrm{kHz}$, the skull vibrates as a mass-spring system. The large parts (temporal bone, maxilla) move in phase. Then, between $1 \mathrm{kHz}$ and $2 \mathrm{kHz}$, the mass-spring behavior becomes affected by and - at higher frequencies - dominated by wave transmission. ${ }^{15}$

Generally, the transmission in direct $\mathrm{BC}$ is recognized as almost linear and proportional to the distance of the vibrator from the HR. ${ }^{16,17}$ However, Sohmer et al. attributed lower hearing thresholds of stimulation at the temporal region containing thinner SB than stimulation at the thicker bone of the forehead. ${ }^{23}$ According to the authors, vibrations can penetrate through to the cranial contents and excite the HR through the CSF pathway. Hoyer and Dorheide also postulated that the stimulated temporal bone surrounded by a frame-like structure may act almost like a membrane. ${ }^{36}$ Therefore, the stimulation of HR in BC cannot be recognized simply as a result of vibratory energy transmission.

\section{Dentaural hearing}

The role of the teeth in the examination of $\mathrm{BC}$, and likely their importance in the process of hearing, is exceptional. The teeth of the maxilla are part of the SB. The mandible then is loosely coupled to the SB by the temporomandibular joint (TMJ). In experiments on tooth stimulation, the importance of the CSF pathway and the participation of STC in the process of hearing has been examined and emphasised. ${ }^{37}$ Though tuning forks were first constructed for musicians, they are presently also used for hearing assessment, especially to estimate the type of hearing loss. ${ }^{38}$ The vibrating fork is usually placed against the mastoid process, pre-auricular region, forehead, skull apex, base of the nose, or mandibular symphysis. Under some circumstances, the results of the most popular Weber test may be inconclusive..$^{10,39}$ In such cases, it is recommended to press the fork against the teeth of the maxilla. $\mathrm{BC}$ is more intense there and the sensation associated with it is clearer. We have found a handful of studies confirming the high efficiency of stimulating HR through the "long" pathway from the teeth to the cochlea. One of the pioneers in this area was Semczuk. ${ }^{34}$ He made a series of experiments on dried skulls and on volunteers with different dental conditions. The author used auscultation to evaluate the conduction of sounds from the skull vault and from the teeth to the temporal bone. He observed that the presence of natural or artificial teeth amplified conduction $(0.5,1,1.5$, and $2 \mathrm{kHz})$. Brown used $\mathrm{DH}$ to estimate bone-hearing thresholds in 2,000 subjects. ${ }^{40} \mathrm{He}$ noticed that maxilla teeth conduct sounds better than those of the mandible, and he believed that this was caused by the direct connection of the maxilla to the skull. Brown made audiograms for $\mathrm{DH}$ at 1,2 , and $3 \mathrm{kHz}$, and the results of his work consistently showed better hearing thresholds compared to conventional audiometric examinations. ${ }^{40}$ Dahlin et al. presented the results of hearing tests between 0.25 and $4 \mathrm{kHz}$ on 4 students. ${ }^{41}$ The upper central incisors, canines and first molars were stimulated. The teeth were more sensitive than the forehead $(5-15 \mathrm{~dB})$ at all frequencies (except $4 \mathrm{kHz}$ ). Stenfelt and Hakansson conducted research on 9 patients with a complete set of their own teeth, who were examined in order to compare hearing thresholds by stimulating bone-anchored hearing aids (BAHA), the mastoid process, and the first 4 incisors of the maxilla. $\mathrm{BC}$ at each site was almost identically efficient at lower frequencies, and the titanium implants only started to gain an advantage at frequencies higher than $1 \mathrm{kHz}{ }^{42}$

One way of passing acoustic energy from the teeth to the IE has not been precisely determined. This does not change the fact that the DH is very efficient at stimulating $\mathrm{HR}$, and a few exciting applications have been made in this area. Dahlin et al., as early as 1971 at the University of California in Los Angeles, presented a wireless intraoral hearing aid. ${ }^{41}$ Some research on using DH for audiological prostheses is still being conducted today. In 2009, a Californian company, Sonitus Medical, presented a system consisting of 2 devices: a microphone located in the EAM and an overlay device placed on the upper molars. The overlay wirelessly received acoustic stimuli and converted them into vibrations which were transmitted through the bone to the IE. ${ }^{43}$ Over $90 \%$ of patients reported being satisfied with the results it provided in a long-term observation. ${ }^{44}$ The main advantage over BAHA was that there was no need for any surgical procedures. ${ }^{45}$ In 2007 , the toy company Hasbro introduced a toothbrush (Tooth Tunes) that vibrated to create the sensation of listening to music inside one's head. It was marketed towards children to encourage them to brush their teeth longer and more thoroughly. ${ }^{46}$ 


\section{Dental pathologies and hearing}

The government of Peru recently launched an instructional campaign, "Always with a smile." The Ministry of Health in the country, where over $90 \%$ of the population suffers from dental problems, set a strategy to help people improve their dental health. A surprising secondary goal of this campaign is the possible beneficial impact on Peruvians' hearing. ${ }^{47}$ Most researchers were in agreement about the harmful effect materials used in dental treatment can have on hearing. ${ }^{34}$ In 2008, Rothvell and Boyd presented the results of hearing assessment in patients where the total amount and area of amalgam fillings were significantly related to increased hearing thresholds. ${ }^{48}$ The correlation was strongest at $14 \mathrm{kHz}$ and increased by $2.4 \mathrm{~dB}$ with every additional filling. The most convincing and unanimous implication seems to be the few publications so far where pathology is expressed as the number of lost teeth. Semczuk was investigating correlations between dental health and hearing in the 1960s and presented two large studies. ${ }^{34}$ One was an analysis of 5,000 patients. Semczuk found that $51 \%$ of toothless patients demonstrated hearing loss. Severe hearing loss (whisper $<0.5 \mathrm{~m}$ ) was observed in $40 \%$ of patients without teeth. Semczuk's second study focused on comparing the hearing thresholds and dental status in 600 otherwise healthy individuals. ${ }^{34}$ Pure tone audiometry revealed normal hearing in $80 \%$ of the subjects with healthy teeth, while $50 \%$ of the patients with only half of their own teeth and only $15 \%$ of toothless subjects had normal hearing thresholds. Semczuk believed that this might be caused by malocclusion, TMJ pathologies, and Eustachian tube dysfunctions. ${ }^{34}$ Schell et al. observed a significant increase in hearing thresholds among toothless patients in comparison to controls with full or almost full dentition ( $\geq 25$ teeth) ${ }^{49}$ They suggested that lower activity of the soft palate tensor resulted in Eustachian tube dysfunction. Lawrence et al. observed a 1.64-fold increase in hearing loss in subjects who had lost more than half of their teeth in comparison to those with less tooth loss. ${ }^{50}$ They suggested that proper occlusion in the vertical dimension might be the most important protective factor. Correlations between dental defects and hearing disorders were investigated by Peeters et al. ${ }^{51}$ Hearing thresholds were significantly higher at $0.125,0.250,4$, and $8 \mathrm{kHz}$ in subjects who had less than 17 teeth, compared to patients with a full set of teeth.

There are also a few publications reporting improved hearing after successful dental treatment. King et al. showed the results of audiometric examination in 2 subjects who had had all of their remaining teeth removed, and then underwent complete prosthetic treatment. ${ }^{52}$ They observed lowered thresholds (AC and $\mathrm{BC}$ ) and increased cochlear reserve after the treatment. Nagasaka et al. presented the results of the treatment of malocclusion followed by habitual unilateral chewing. ${ }^{53}$ After stomatologic training, all 5 subjects presented improved air hearing thresholds for the full range of frequencies $(0.25-8 \mathrm{kHz})$ on the affected side. Kempf et al. noticed diminished IE symptoms (hearing loss, tinnitus, and vertigo) in over half $(56.5 \%)$ of patients after dental treatment. ${ }^{54}$ Almost every time, the authors recommended a detailed dental assessment in patients with IE disorders of unknown etiology.

Some researchers proved that chewing simultaneously stimulated muscular activity, increased blood flow through the central nervous system, and increased neuronal activity. ${ }^{55-57}$ Observations documenting the relationship between dental pathologies and aging, including the aging of the hearing organ, are not very surprising. It was suggested that poor dental health might contribute to the development of dementia in senility. However, many other conditions may contribute to dental defects, including poor dietary habits or chronic systemic conditions. ${ }^{58}$ Tooth loss is also suggested to be a risk factor of Alzheimer's disease. Having no teeth, together with a lack of mental and physical activity, poor education, and previous head injuries, very greatly increases the probability of falling ill. ${ }^{59}$ In these pathologies, hearing defects may likely be connected with poor results in speech audiometry.

\section{Summary of findings}

Auditory stimulation in AC, BC, and STC can interact with each other. Different vibrations of the $\mathrm{SB}$ and impaired $\mathrm{BC}$ could possibly influence the air-hearing threshold. Maxilla teeth are a very sensitive stimulating site of the HR in BC. Additionally, dental pathologies - especially the loss of teeth - and the results of dental treatment have a noticeable impact on hearing acuity. Hearing disorders, which interfere with dental health, are therefore the most probable at lower frequencies (from $0.3-0.4 \mathrm{kHz}$ to $2 \mathrm{kHz}$ ), where the skull segments like the maxilla bone and teeth vibrate separately. In this range, the inertial mechanisms are currently recognized as the most valid in $\mathrm{BC}$ hearing.

\section{References}

1. Rossi G, Solero P, Rolando M, Olina M. Delayed oto-acoustic emissions evoked by bone-conduction stimulation: Experimental data on their origin, characteristics and transfer to the external ear in man. Scand Audiol Suppl. 1988;29:1-24.

2. Lenhardt ML, Skellett R, Wang P, Clarke AM. Human ultrasonic speech perception. Sci. 1991;253:82-85.

3. Adelman C, Fraenkel R, Kriksunov L, Sohmer H. Interactions in the cochlea between air conduction and osseous and non-osseous bone conduction stimulation. Eur Arch Otorhinolaryngol. 2012;269:425-429.

4. Rosowski JJ, Merchant SN. Mechanical and acoustic analysis of middle ear reconstruction. Am J Otolaryngol. 1995;16:486-497.

5. Puria S, Peake WT, Rosowski JJ. Sound-pressure measurements in the cochlear vestibule of human-cadaver ears. J Acoust Soc Am. 1997;101:2754-2770.

6. Ravicz ME, Rosowski J, Voigt HF. Sound-power collection by the auditory periphery of the Mongolian gerbil Meriones unguiculatus. I: Middle-ear input impedance. J Acoust Soc Am. 1992;92:157-177. 
7. Bucchman E, Rosenhouse G, Shupak A, Shimoni U. On the transmission of sound generated by an electromagnetic device from the mastoid process to the petrous bone. J Acoust Soc Am. 1991;90:895-903.

8. Håkansson $B$, Carlsson $P$, Tjellström A. The mechanical point impedance of the human head, with and without skin penetration. J Acoust Soc Am. 1986;80:1065-1075.

9. Gerhardt KJ, Huang X, Arrinton KE, Meixner K, Abrams RM, Antonelli PJ. Fetal sheep in utero hear through bone conduction. Am J Otolaryngol. 1996;17:374-379.

10. Miodoński J. A simple differential test between the conduction and the perception disorders. Otolaryngol Pol.1954;8:211-214 [in Polish].

11. Adelman C, Sohmer H. Thresholds to soft tissue conduction stimulation compared to bone conduction stimulation. Audiol Neurootol. 2013;18:31-35.

12. Khanna SM, Tonndorf J, Queller JE. Mechanical parameters of hearing by bone conduction. J Acoust Soc Am. 1976;60:139-154.

14. Reinfeldt S, Stenfelt S, Good T, Håkansson B. Examination of boneconducted transmission from sound field excitation measured by thresholds, ear-canal sound pressure, and skull vibrations. J Acoust Soc Am. 2007;121:1576-1587.

15. Stenfelt S. Acoustic and physiologic aspects of bone conduction hearing. Adv Otorhinolaryngol. 2011;71:10-21.

16. Stenfelt S, Goode RL. Transmission properties of bone conducted sound: Measurements in cadaver heads. J Acoust Soc Am. 2005;118:2373-2391.

17. Eeg-Olofsson M, Stenfelt S, Tjellström A, Granström G. Transmission of bone-conducted sound in the human skull measured by cochlear vibrations. Int J Audiol. 2008;47:761-769.

18. Algarra MJ, Ventura MA. Physiology of bone conduction acoustic stimulation and the importance of high-frequency bone conduction. Acta Otorrinolaringol Esp. 2008;59:3-6 [in Spanish].

19. Stenfelt $\mathrm{S}$. Middle ear ossicles motion at hearing thresholds with air conduction and bone conduction stimulation. Review. J Acoust Soc Am. 2006;119:2848-2858.

20. Tsai V, Ostroff J, Korman M, Chen JM. Bone-conduction hearing and the occlusion effect in otosclerosis and normal controls. Otol Neurotol. 2005;26:1138-1142.

21. Stenfelt S, Wild T, Hato N, Goode RL. Factors contributing to bone conduction: The outer ear. J Acoust Soc Am. 2003;113:902-913.

22. Freeman S, Sichel JY, Sohmer H. Bone conduction experiments in animals - evidence for a non-osseous mechanism. Hear Res. 2000;146:72-80.

23. Sohmer H, Freeman S, Geal-Dor M, Adelman C, Savion I. Bone conduction experiments in humans - A fluid pathway from bone to ear. Hear Res. 2000;146:81-88.

24. Sichel JY, Freeman S, Sohmer H. Lateralization during the Weber test: Animal experiments. Laryngoscope. 2002;112:542-546.

25. Kaufmann M, Adelman C, Sohmer H. Mapping at sites on bone and soft tissue of the head, neck and thorax at which a bone vibrator elicits auditory sensation. Audiol Neurotol Extra. 2012;2:9-15.

26. Ito T, Roosli C, Kim CJ, Sim JH, Huber AM, Probst R. Bone conduction thresholds and skull vibration measured on the teeth during stimulation at different sites on the human head. Audiol Neurootol. 2011;16:12-22.

27. Chordecar S, Kriksunov L, Kishon-Rabin L, Adelman C, Sohmer H. Mutual cancellation between tones presented by air conduction, by bone conduction and by non-osseous (soft tissue) bone conduction. Hear Res. 2012;283:180-184.

28. De Jong M, Perez R, Adelman C, et al. Experimental confirmation that vibrations at soft tissue conduction sites induce hearing by way of a new mode of auditory stimulation. J Basic Clin Physiol Pharmacol. 2011;26:55-58.

29. Obrębowski A. The application of acumetric hearing tests methods with tuning forks. In: Pruszewicz A, Obrębowski A, eds. Clinical Audiology. $2^{\text {nd }}$ ed. Poznań: Wydawnictwa Akademii Medycznej im. Karola Marcinkowskiego; 2010:171-181 [in Polish].

30. Khalil TB, Viano DC, Smith DL. Experimental analysis of the vibrational characteristics of the human skull. J Sound Vib. 1979;63:351-376.

31. Young PG. A parametric study on the axisymmetric modes of vibration of multi-layered spherical shells with liquid cores of relevance to head impact modeling. J Sound Vib. 2002;256:665-680.

32. Von Békésy G. Zur Theorie des Horens bei der Schallaufnahme durch Knochenleitung. Ann Phys. 1932;13:11-136 [in German].
33. Huizing $\mathrm{EH}$. Bone conduction - The influence of the middle ear. Acta Otolaryngol. 1960;155:1-99.

34. Semczuk B. Studies on the role of the state of dentition in the physiopathology of the auditory organ. II-IV. Ann Univ Mariae Curie Sklodowska Med. 1967;22:153-178 [in Polish].

35. Howell P, Williams M, Dix H. Assessment of sound in the ear canal caused by movement of the jaw relative to the skull. Acta Otolaryngol. 1988;17:93-98.

36. Hoyer HE, Dorheide J. A study of human head vibrations using time-averaged holography. J Neurosurg. 1983;58:729-733.

37. Ozer E, Adelman C, Freeman S, Sohmer H. Bone conduction hearing on the teeth of the lower jaw. J Basic Clin Physiol Pharmacol. 2002;13:89-96.

38. Feldmann H. History of the tuning fork I-III. Laryngorhinootol. 1997;76:116-134.

39. Behn A, Westerberg BD, Zhang H, Riding KH, Ludemann JP, Kozak FK. Accuracy of the Weber and Rinne tuning fork tests in evaluation of children with otitis media with effusion. J Otolaryngol. 2007;36:197-202.

40. Brown LA. Dentaural Hearing Testing: Calibrating bone conduction through the teeth. Ann Otol Rhinol Laryngol. 1969;78:1058-1061.

41. Dahlin GC, Allen FG, Collard EW. Bone-conduction thresholds of human teeth. J Acoust Soc Am. 1973;53:1434-1437.

42. Stenfelt SP, Håkansson BE. Sensitivity to bone-conducted sound: Excitation of the mastoid versus the teeth. Scand Audiol. 1999;28:190-198.

43. Sonitus Medical Inc. 2010. Online information available at The SoundBite system. http://www.sonitusmedical.com. Accessed on 2013.

44. Murray M, Miller R, Hujoel P, Popelka GR. Long-term safety and benefit of a new intraoral device for single-sided deafness. Otol Neurotol. 2011;32:1262-1269.

45. Miller R, Hujoel P, Murray M, Popelka GR. Safety of an intra-oral hearing device utilizing a split-mouth research design. J Clin Dent. 2011;22:159-162.

46. Arm \& Hammer. 2012. Online information avbout product http://www.spinbrush.com/Toothtunes.html. Accessed on 2017.

47. Hoffman B, Lorens G, Poremski T. Impaired dentition has impact on hearing loss. Słuch. 2010;72:8.

48. Rothvell JA, Boyd PJ. Amalgam dental fillings and hearing loss. Int J Audiol. 2008;47:770-776.

49. Schell $C L$, Diehl RL, Holmes $A E$, et al. An association between dentate status and hearing acuity. Spec Care Dent. 1999;19:208-213.

50. Lawrence HP, Garcia RI, Essick GK, et al. A longitudinal study of the association between tooth loss and age-related hearing loss. Spec Care Dent. 2001;21:129-140.

51. Peeters J, Naert I, Carette E, Manders E, Jacobs R. A potential link between oral status and hearing impairment: Preliminary observations. J Oral Rehabil. 2004;31:306-310.

52. King WH, Burton MC, Tucker KM. Clinical manifestations of dentaural hearing. J Prosthet Dent. 1974;32:130-140.

53. Nagasaka H, Matsukubo T, Takaesu Y, Kobayashi Y, Sato T, Ishikawa T. Changes and equalization in hearing level induced by dental treatment and instruction in bilaterally equalized chewing: A clinical report. Bull Tokyo Dent Coll. 2002;43:243-250.

54. Kempf HG, Roller R, Mühlbradt L. Correlation between inner ear disorders and temporomandibular joint diseases. HNO. 1993;41:7-10.

55. Abrams R, Hammel HT. Hypothalamic temperature in anaesthetized albino rats during feeding and sleeping. Am J Physiol. 1964;206:641-646.

56. Momose T, Nishikawa J, Watanabe TS, et al. Effect of mastication on regional cerebral blood flow in humans examined by positronemission tomography with ${ }^{15} \mathrm{O}$-labelled water and magnetic resonance imaging. Arch Oral Biol. 1997;42:57-61.

57. Rampone AJ, Shirasu ME. Temperature changes in the rat in response to feeding. Sci. 1964;144:317-319.

58. Stein PS, Desrosiers M, Donegan SJ, Yepes JF, Kryscio RJ. Tooth loss, dementia and neuropathology in the Nun Study. J Am Dent Assoc. 2007;138:1314-1322.

59. Kondo K, Niino M, Shido K. A case-control study of Alzheimer's disease in Japan - Significance of life-styles, Dementia. 1994;5:314-326. 